\title{
NEPHROSIS: A CLINICAL AND HISTOLOGICAL STUDY OF 38 CHILDREN
}

\author{
BY \\ R. MCLAREN TODD and M. J. BOUTON \\ From the Department of Child Health, Liverpool University, and Alder Hey Children's Hospital, Liverpool
}

(RECEIVED FOR PUBLICATION MARCH 29, 1965)

Many attempts have been made to classify renal diseases in general and glomerulonephritis in particular since Richard Bright (1836) reported his classical researches into the clinical and pathological changes in his patients suffering from kidney disease. The word nephrosis was coined by Müller (1905) to define a clinical condition characterized by oedema, albuminuria, and hypoproteinaemia. Volhard and Fahr (1914) classified Bright's disease into three groups, (A) nephrosis, (B) nephritis, and (C) arteriosclerosis. The best known classification in this country is that of Ellis (1942) who divided nephritis into types 1 and 2 : its great merit was that it attempted to correlate clinical features with histological changes. In our experience, however, it is often impossible to divide renal lesions into these two types, for there are often transitions from one type to another, and even the correlation between histological features and clinical findings is poor. The attempts by Dodge, Daeschner, Rosenberg, Brennan, Travis, and Hopps (1962) to introduce modifications of the Ellis system only lead to further confusion, especially when comparing their results with those of other workers. We have, therefore, come to the conclusion that the only helpful classification of nephritis is one based on descriptive morphology; in our experience this classification is of considerable help in prognosis, though it might not be of as much assistance in unravelling the aetiology of this group of diseases. It is likely that the kidney responds in much the same way to a variety of insults, but some of the changes may be permanent, some may develop slowly over a period of years, some may be progressive, and yet others may resolve completely. We believe that renal biopsy may be of considerable help in prognosis by providing evidence of the types of changes occurring in the kidney.

The patients we have studied have all shown clinical evidence of nephrosis. We apply this term to patients presenting a characteristic group of symptoms, signs, and biochemical features, i.e. oedema, albuminuria, hypoproteinaemia, and hypercholesterolaemia; all are often of insidious onset and vary in degree over a period of years. This clinical view of nephrosis is well described by Kramer, Goldman, and Cason (1952), who add that nephrosis occupies a position shared by few diseases in medicine: its aetiology is unknown, its course unpredictable, its prognosis uncertain, and its treatment unsatisfactory.

Over the past decade knowledge of the natural history of nephrosis has increased, due in no small measure to the improved biochemical and histological techniques which have been employed, and treatment has been more satisfactory since corticosteroids became available. It is our purpose in presenting the clinical, biochemical, and histological features of 38 children suffering from nephrosis to suggest that a more accurate diagnosis is possible, a more valid prognosis can be made, and the response to corticosteroids can be predicted.

\section{Clinical Features}

The patients were all seen at Alder Hey Children's Hospital, Liverpool; 25 were boys and 13 were girls. The age at onset of the illness varied from 14 months to $13 \frac{1}{2}$ years, but as is shown in Fig. 1, 25 of the children were below the age of 6 years when first admitted to hospital; they have been followed up in the out-patient department for periods up to 10 years. The illness did not have a seasonal incidence and was not more common in the winter months when respiratory infections were prevalent, the onset of symptoms in half the patients being in the months of October to March and in the other half from April to September. There was, however, a history of pyrexial illness within 1 month of the onset of nephrosis in 27 of the 38 patients; 24 of them gave a history of a cold, tonsillitis, or otitis, 2 of them had 


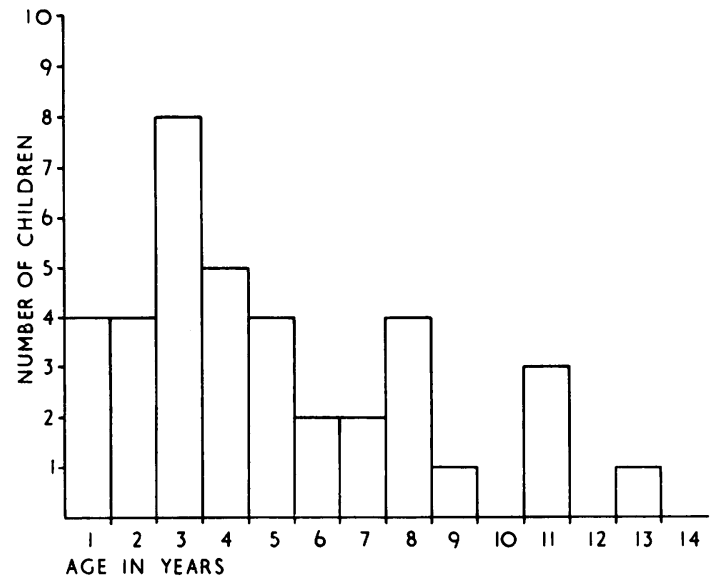

FIG. 1.-Age distribution of 38 children suffering from nephrosis.

recently recovered from gastro-enteritis, and 1 had suffered from boils.

The presenting symptoms were oedema in 36 patients, pallor in 17 , abdominal pain in 11 , vomiting in 7 , and a rash in 3.

At the initial clinical examination all patients except 2 had oedema of variable degree: in 3 patients it was minimal, i.e. slight puffiness of the eyelids; in 13 it was moderate, i.e. pitting oedema of shins or feet; and in 20 it was severe, i.e. there were localized collections of fluid either in the peritoneal cavity, pleural cavity, or scrotum. Blood pressure was normal in 21 and raised in 17 patients. Albuminuria was present in all 38 patients: it was recorded as + in $5,++$ in 4 , and +++ in 29 patients; red blood cells in excess of 10 per $1 / 6$ field were present in 6 patients (Table 1).

\section{Investigations}

Throat swabs were taken from 32 patients: in 27 no pathogenic organisms were grown, in 4 haemolytic streptococci were isolated, and in 1 Haemophilus parainfluenzae was isolated.

Blood urea was below $40 \mathrm{mg} . / 100 \mathrm{ml}$. in all patients except 7 , in whom it was between 40 and 50 $\mathrm{mg} . / 100 \mathrm{ml}$.

Total serum protein estimations and electrophoretic fractionations were carried out in all 38 patients and serum cholesterol values were measured in 34 patients. The total serum protein levels were subnormal in all except 2 patients; there was marked reduction in the levels of albumin, some reduction in $\gamma$-globulins, and an increase in $\alpha_{2}$-globulins. These changes are recorded in Fig. 2 and are related to the histological features obtained at renal biopsy. It will be seen that in the membranous type of nephrosis the total serum protein levels were not as low as in the other types, and the $\gamma$-globulin levels were normal or above normal in 4 of the 6 patients with membranous nephrosis.

Renal biopsy was performed in all 38 patients. Jungmann in 1924 was the first person to report his results of renal biopsies which were obtained during the course of abdominal operations. Percutaneous needle biopsy was first used by Nils Alwall of the University of Lund in 1944, but publication of his results was delayed until 1952. A relatively small amount of renal tissue is obtained by percutaneous biopsy, and the specimen may be torn or fragmented.

TABLE 1

DETAILS OF 38 CASES OF NEPHROSIS GROUPED ACCORDING TO RENAL HISTOLOGY

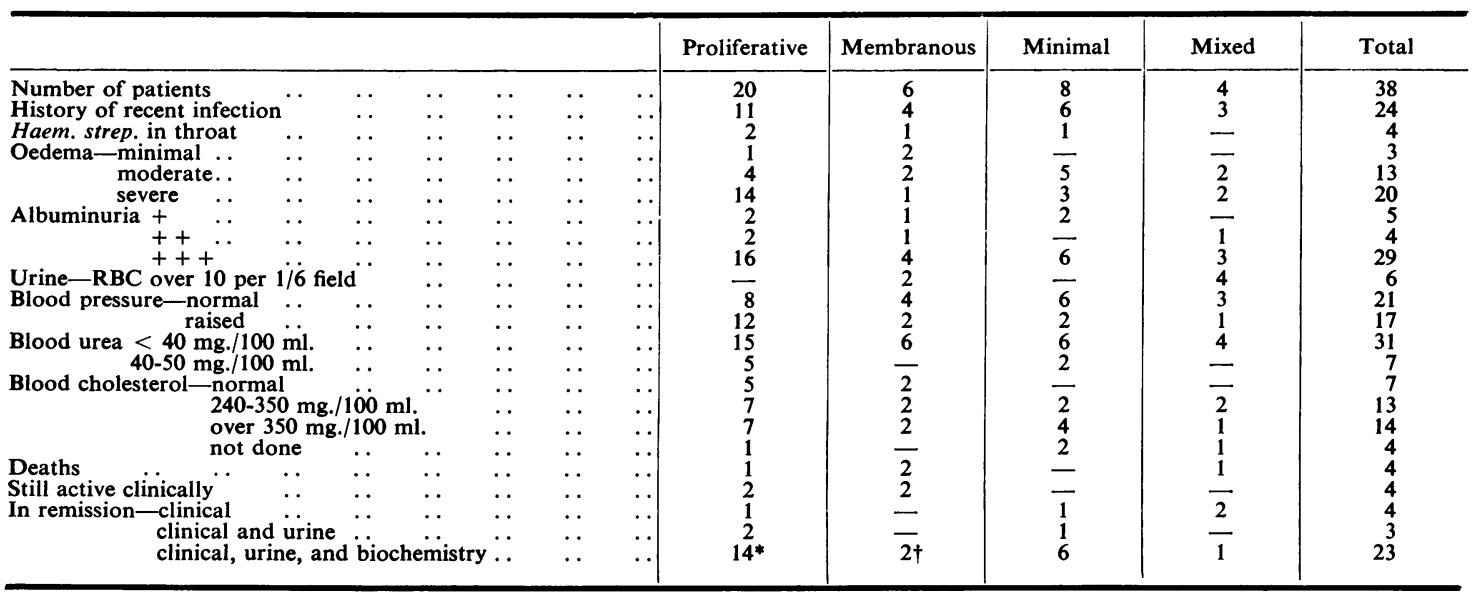

* Four off treatment. † One off treatment. 


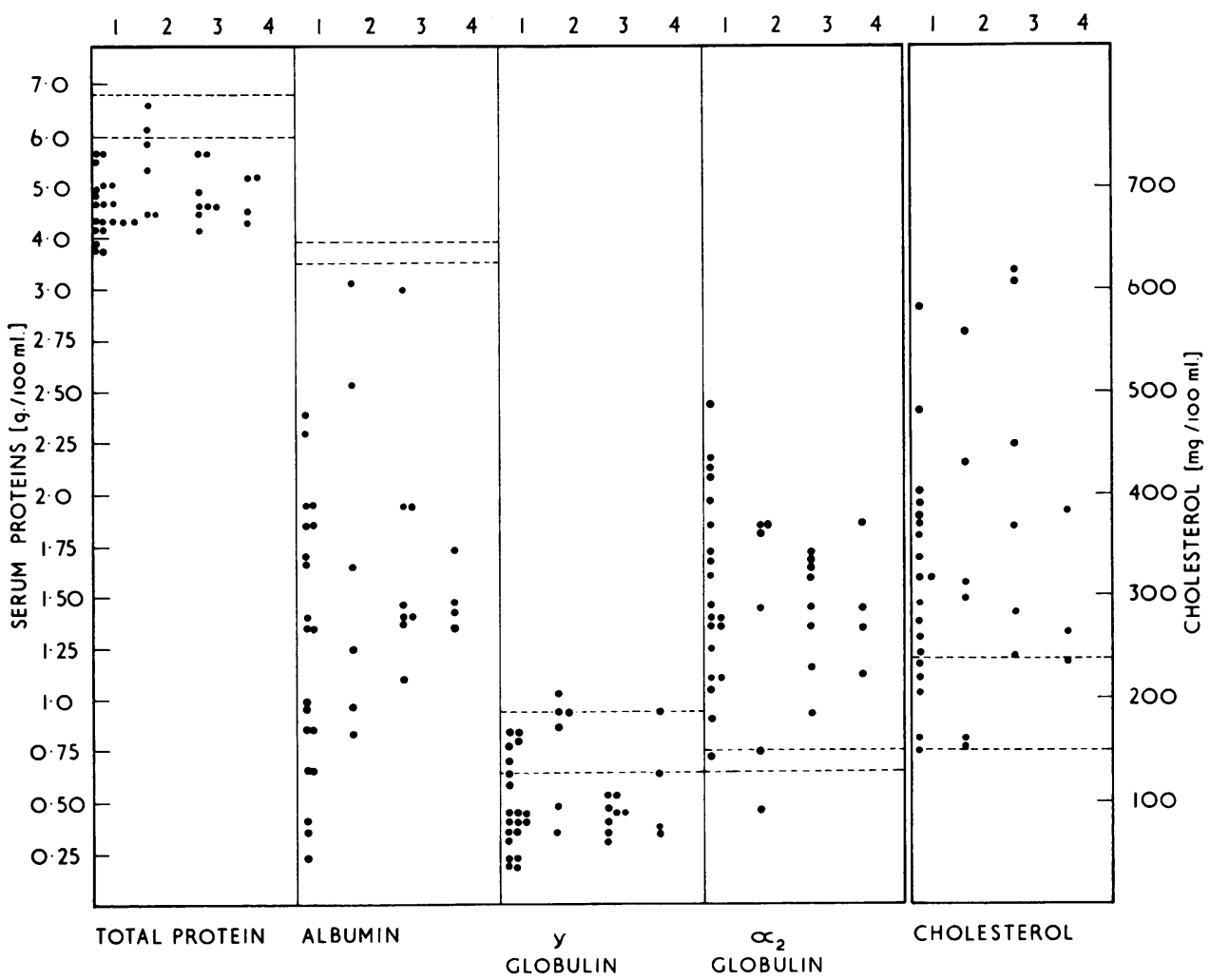

Fig. 2.-Serum proteins-total and fractional, and cholesterol levels in 38 cases of nephrosis grouped according to renal histology. (1) Proliferative. (2) Membranous. (3) Minimal. (4) Mixed. Broken lines indicate normal ranges.

It has been our practice to enlist the help of our surgical colleague, Mr. Herbert Johnston, to obtain a specimen of renal tissue by open biopsy. This entails a small incision in the loin not more than 1 in. $(2 \cdot 5 \mathrm{~cm}$.) long, exposure of the kidney, and removal of 0.25 in. $(0.6 \mathrm{~cm}$.) cube of renal cortex under direct vision. The renal tissue contains 25 to 30 glomeruli per section, the specimen is not fragmented, and no serious complications have been observed. There was some delay in wound healing in a few patients who at the time of biopsy had massive oedema and who were already on treatment with corticosteroids. The histological features enabled us to divide the material into 4 types.

Minimal proliferative. This is probably identical with 'lipoid nephrosis'. The glomeruli show very little histological abnormality, but careful analysis will often show that there may be proliferation of nuclei in some of the glomeruli, or some reduction in the number of open capillary loops. They are filled by an eosinophilic material which probably represents a swelling of the mesangium.
Proliferative. All the changes described above are present but are more marked. The number of nuclei in the glomerular tuft is increased, but we have not found it possible to differentiate those of endothelial from those of epithelial origin. There is increased staining of the mesangium and the capillary lumen no longer appears patent. There is some rigidity of the basement membrane, which may be slightly thickened focally. There is diminution of the capsular space and synechiae are quite frequent. In a minority of cases there is proliferation of the cells lining Bowman's capsule, and crescents can be seen. We do not consider their presence to have any sinister significance, as implied by Ellis, but only that they indicate a more severe reaction. Nor could their frequency be correlated with the length of the disease process.

Periodic acid-Schiff staining reveals an increase in PAS-positive material in the tuft, which is mainly deposited like fibrils throughout the mesangium. They are probably the early stages of fibrillary scars. This group is very heterogeneous and probably contains aetiologically different diseases. It is not 
surprising, therefore, that it is this group that has given rise to most controversy, and has a less clear prognosis. But if it is remembered that the disease is in a staie of 'flux' and can resolve or progress, much of the controversy is easily explained. In our experience with children the prognosis, as will be seen later, is good; but in adults the prognosis may be different (Kark, Pirani, Pollak, Muehrcke, and Blainey, 1958; Blainey, Brewer, Hardwicke, and Soothill, 1960).

Proliferative changes are sometimes focal, that is to say they are confined to one or two lobules of the glomerulus and often to only a few glomeruli. Although we have found these changes more often in patients who present with haematuria (Bouton and Todd-to be published), they also occur in some patients with the clinical and biochemical features of nephrosis.

This focal lesion is basically the same as that which occurs in Schönlein-Henoch purpura (Heptinstall, 1960), but when nephrotic features arise the glomerular lesion may become more generalized and epithelial crescents may be seen; it is still possible, however, to recognize focal scars in areas of focal lobular accentuation of proliferation, and differences between the glomeruli in the degree of involvement.

Membranous. This group is the easiest to recognize. Our criteria have been diffuse thickening of the basement membrane without any accompanying proliferation of nuclei. The thickening is usually marked and must not be confused with the rigidity which is often present in mainly proliferative cases. This thickening stains positively with PAS, but not infrequently the original basement membrane stains distinctly and the 'thickening' appears to consist of a material that has been deposited against the basement membrane, rather than a thickening of the original membrane. This type of lesion is permanent and can be progressive.

Mixed. It is not surprising that a number of cases show changes that are mainly proliferative in some glomeruli but mainly membranous in others. Two patients with clinical features of nephrosis also had evidence of Schönlein-Henoch purpura, and histological examination showed that mixed changes were present. They showed clinical improvement after prolonged steroid therapy, the serum proteins became normal, but a small amount of albumin persisted in the urine. It is pertinent here to point out that the proliferative changes in these patients and in other patients who did not have nephrosis were very marked, and included proliferation of extracapillary Bowman's membrane epithelium and numerous crescents. These changes were indistinguishable from those described in the so-called progressive form of Ellis type I subacute nephritis, and are further evidence that this classification is unworkable, as most of them have recovered clinically and have not yet developed chronic nephritis.

\section{Treatment}

The main objectives in the treatment of our patients have been (i) to increase the level of serum proteins; (ii) to eliminate oedema; (iii) to prevent infections, especially those caused by pneumococci and streptococci; and (iv) to sustain the morale of patients and their parents in what is a long-term illness, often punctuated by exacerbations and remissions. We have attempted to achieve these objectives by the following four methods: (a) the provision of a high-protein, low-salt diet, supplemented in 3 patients by intravenous infusions of saltfree plasma; (b) the prophylactic use of penicillin given orally, in a dosage of 200,000 units twice daily, for a period of years; (c) the use of diuretics: hydrochlorothiazide was given to 9 patients, chlorothiazide to 6 , spironolactone to 8 , and frusemide to 1 ; and (d) the use of corticosteroids.

Prednisolone was the only corticosteroid given to 23 patients; in a further 9 patients it was given initially but changed to a water-soluble corticosteroid, e.g. prednisol, triamcinolone, because of lack of clinical response; in a further 3 patients prednisolone was given after a short course of ACTH, and in 3 patients corticosteroids other than prednisolone were given. The corticosteroid used reflected the preference of the paediatrician in charge of the patient, but prednisolone was usually preferred.

The initial dosage of prednisolone was 50 to 75 mg. daily and it was continued as a rule for 2 weeks until clinical response was obtained, and then gradually reduced over a period of 4 to 6 weeks to a maintenance dose of $7 \frac{1}{2}$ to $10 \mathrm{mg}$.; the maintenance dose was continued usually for years until the results of urine and blood analysis showed normality; in one patient prednisolone was discontinued after 10 weeks and during the subsequent 4 years he has not had a relapse either clinical or biochemical.

\section{Response to Treatment}

Initial clinical response to steroid therapy occurred within a month in all patients except two, one with membranous changes and one with proliferative changes and necrotizing glomerulitis, and both these patients died. Relapse, indicated by recurrence of oedema and increase of albuminuria, was a common feature in all 4 groups. Relapse occurred on 58 occasions in 20 survivors in the proliferative group over an aggregate period of 91 patient years, i.e. an 
average of 1 relapse per patient every 18 months; in the membranous group of 6 patients, there were 2 deaths, 2 patients remained active clinically, 2 responded initially but 1 of them relapsed; in the minimal group there were 17 relapses in 8 patients in 31 years, i.e. 1 relapse per patient every 23 months; in the 4 patients showing mixed changes there was 1 death and relapse occurred in 2 of the survivors within 1 year of initial diagnosis.

Complications were observed in 3 patients; one patient developed osteoporosis of the spine after he had been on prednisolone for 4 years, and 2 patients developed pneumococcal peritonitis in spite of prophylactic penicillin therapy.

Recovery was judged by three criteria, namely clinical disappearance of oedema, cessation of albuminuria, and return to biochemical normality. Complete clinical, urinary, and biochemical recovery occurred in 14 patients in the proliferative group and 4 of these patients have stopped steroids; in a further 2 patients, clinical and urinary examination was negative but serum protein levels were not completely normal, and in 2 patients there was no oedema but albuminuria persisted and serum proteins were abnormal; 2 patients continued to have active clinical disease.

Complete recovery occurred in 2 of the 6 patients with membranous changes, 6 of 8 patients with minimal changes, and 1 of 3 patients with mixed changes. Death occurred in 4 of the 38 patients. One patient, agirl of 2 years, had proliferative changes with necrotizing glomerulitis: she was unresponsive to steroids and died in cardiac failure $5 \frac{1}{2}$ months after the onset of symptoms. The second death was in a girl aged $13 \frac{1}{2}$ years with membranous changes which failed to respond to steroids: she became hypertensive and died 18 months after the onset of the illness. The third death occurred in a boy aged 5 years with mixed changes, who was treated with steroids but who died 3 months after onset of symptoms. The fourth death occurred in a boy with membranous changes with a clinical history of 6 months' duration, who was unresponsive to steroids.

\section{Discussion}

The main problems encountered in patients suffering from nephrosis are those concerned with (a) diagnosis, (b) treatment, and (c) prognosis.

(a) Diagnosis. Oedema, albuminuria, hypoproteinaemia, and hypercholesterolaemia are the clinical features of nephrosis, but these four abnormalities do not give any indication of the underlying cause. Kark et al. (1958) state that in adults there are 40 disease states which can produce nephrosis: in 46 of their 98 patients nephrosis was due to intrinsic renal disease, i.e. glomerulo-nephritis, but in others it was due to systemic diseases such as lupus erythematosus, amyloidosis, diabetes mellitus, Schönlein-Henoch purpura, drugs, e.g. mercury, gold, tridione, in which the renal involvement was but one element. Thus renal biopsy enables a more accurate diagnosis to be made.

Estimation of the levels of $\gamma$ - and $\alpha_{2}$-globulins together with level of blood cholesterol may indicate whether membranous changes are present; in the membranous type $\gamma$-globulin may be above normal, $\alpha_{2}$-level may not be raised excessively, and cholesterol may be normal. In contrast, in patients showing proliferative changes at biopsy, the $\alpha_{2}$-level is raised often in excess of $1 \mathrm{~g}$. $/ 100 \mathrm{ml}$., $\gamma$-globulin level is reduced and serum cholesterol level is often raised to $300 \mathrm{mg} . / 100 \mathrm{ml}$. or more.

(b) Treatment. Many forms of therapy have been advocated for nephrosis; in their review of treatment used at the Children's Medical Center, Boston, Mass. during the years 1926 to 1948 , Barness, Moll, and Janeway (1950) list 64 forms of treatment. There is general agreement that steroids have proved of considerable value in the treatment of nephrosis in childhood, and in most patients oedema disappears, and other clinical and biochemical changes indicate a favourable response to steroids. In adults, however, the outlook is not so favourable. Ross and Smith (1963) followed for a period of 5 years the progress of 26 adults treated with steroids; 4 responded by complete loss of proteinuria, in 7 proteinuria was reduced to less than $1 \mathrm{~g}$. per litre, but in 15 patients failure to respond to steroids was reported. There are certain disadvantages in the prolonged use of steroids, such as stunting of growth, moon face, striae, osteoporosis, hypocalcaemia, and eye changes. Renal biopsy may be of help in deciding whether response to steroids is likely to occur; when proliferative changes are present, response to steroids usually occurs, but when membranous changes are already present it is unlikely that they will be influenced by steroids.

Relapses are frequently encountered in patients suffering with nephrosis and they are often provoked by certain infections. Respiratory tract infections will often be followed by reappearance of oedema and other signs of activity; when these infections are bacterial in origin, e.g. streptococcal, penicillin may be helpful in prophylaxis, but when epidemic viral infections are prevalent no form of chemoprophylaxis is of avail.

(c) Prognosis. It is extremely difficult in children suffering from nephrosis to give a direct answer to 
TABLE 2

OUTCOME OF 590 CASES OF NEPHROSIS ACCORDING TO VARIOUS TYPES OF TREATMENT

\begin{tabular}{|c|c|c|c|c|c|c|c|c|c|}
\hline \multirow{2}{*}{ Author } & \multirow{2}{*}{ Area } & \multirow{2}{*}{ Date } & \multirow{2}{*}{$\begin{array}{c}\text { No. } \\
\text { of } \\
\text { Patients }\end{array} \mid$} & \multicolumn{2}{|c|}{ Well } & \multicolumn{2}{|c|}{ Active } & \multicolumn{2}{|c|}{ Deaths } \\
\hline & & & & No. & $\%$ & No. & $\%$ & No. & $\%$ \\
\hline Barness et al. (1950) & Boston, Mass. & $\begin{array}{l}1926 \text { to } 1938 \text { (pre-chemotherapy) } \\
1939 \text { to } 1942 \text { (sulphonamides) } \\
1943 \text { to } 1948 \text { (penicillin) }\end{array}$ & $\begin{array}{l}40 \\
32 \\
64\end{array}$ & $\begin{array}{r}17 \\
9 \\
18\end{array}$ & $\begin{array}{l}42 \cdot 5 \\
28 \\
28\end{array}$ & $\begin{array}{r}6 \\
2 \\
17\end{array}$ & $\begin{array}{r}15 \\
7 \\
27\end{array}$ & $\begin{array}{l}17 \\
21 \\
29\end{array}$ & $\begin{array}{l}42 \cdot 5 \\
65 \\
45\end{array}$ \\
\hline $\begin{array}{l}\text { Schwarz, Kohn, and } \\
\text { Weiner (1943) }\end{array}$ & New York & 1922 to 1942 & 40 & 12 & 30 & 6 & 15 & 22 & 55 \\
\hline Lawson et al. (1960) & London & $\begin{array}{c}1917 \text { to } 1938 \text { (pre chemotherapy) } \\
1945 \text { to } 1957: \text { no steroids } \\
\text { steroids }\end{array}$ & $\begin{array}{l}78 \\
62 \\
40\end{array}$ & $\begin{array}{l}? 41 \\
33 \\
16\end{array}$ & $\begin{array}{l}53 \\
53 \\
40\end{array}$ & $\overline{9}$ & $\begin{array}{l}\overline{15} \\
15\end{array}$ & $\begin{array}{r}? 37 \\
20 \\
18\end{array}$ & $\begin{array}{l}47 \\
32 \\
45\end{array}$ \\
\hline Arneil (1961) $\quad$. & Glasgow & $\begin{array}{l}1929 \text { to } 1936 \text { (low sodium diet, pre-sulphonamide) } \\
1937 \text { to } 1945 \text { (sulphonamides) } \\
1946 \text { to } 1950 \text { (penicillin, etc.) } \\
1951 \text { to } 1955 \text { (cortisone, ACTH) } \\
1955 \text { to } 1957 \text { (prednisolone) }\end{array}$ & $\begin{array}{l}11 \\
41 \\
37 \\
53 \\
22\end{array}$ & $\begin{array}{r}3 \\
13 \\
18 \\
26 \\
14\end{array}$ & $\begin{array}{l}28 \\
32 \\
48 \\
42 \\
64\end{array}$ & $\begin{array}{r}4 \\
14 \\
5 \\
18 \\
6\end{array}$ & $\begin{array}{l}36 \\
34 \\
14 \\
39 \\
27\end{array}$ & $\begin{array}{r}4 \\
14 \\
14 \\
9 \\
2\end{array}$ & $\begin{array}{r}36 \\
34 \\
38 \\
19 \\
9\end{array}$ \\
\hline Todd (1957) $\quad .$. & Liverpool & 1948 to 1955 ( $50 \%$ given steroids) & 32 & 14 & 44 & 7 & 22 & 11 & 34 \\
\hline \multirow[t]{2}{*}{$\begin{array}{c}\text { Todd and Bouton (this } \\
\text { investigation) }\end{array}$} & Liverpool & 1956 to 1964 (steroids) & 38 & 30 & 78 & 4 & 11 & 4 & 11 \\
\hline & & & 590 & 264 & 44 & 104 & 18 & 222 & 38 \\
\hline
\end{tabular}

the parents' request to indicate the probable course of the illness or its length, but certain factors are of considerable help in forming a prognostic judgement. A severe degree of oedema by no means indicates a bad prognosis, neither is prognosis worse if albuminuria is marked. In 6 patients red blood cells were present in the urine in excess of 10 per $1 / 6$ field, and in many of these red cells exceeded 100 per $1 / 6$ field, in 4 of these 6 patients there was either no response or a poor response to steroids; thus in our experience haematuria is a poor prognostic sign. Serum cholesterol levels were usually raised, but in 8 patients levels were normal; the response of all but 1 of these 8 patients to treatment was poor and suggests that estimation of the cholesterol level is of prognostic value. Blainey et al. (1960) in their study of nephrotic syndrome in adults found that the highest values for serum cholesterol were obtained in those patients who responded best to treatment.

Long-term follow up of patients suffering from nephrosis indicates the improved prognosis, as judged by mortality, resulting from the introduction first of sulphonamides and later of antibiotics; further improvement in prognosis has resulted from the introduction of steroids. Table 2 lists the results of treatment of 590 children suffering from nephrosis, and relates the results to the form of therapy used. The over-all mortality rate is $38 \%$ and the 'cure' rate $44 \%$, using the term 'cure' for absence of clinical evidence of disease when assessed at least 3 years after the onset of the illness. Following the introduction of chemotherapeutic agents there was a slight improvement in prognosis, while with the introduction of steroids the mortality rate has been reduced by half and the 'cure' rate has increased.
The percentage of deaths in the series of patients recorded in Table 2 was $45 \%$ before chemotherapy, $43 \%$ with chemotherapy but without steroids, and $21 \%$ with chemotherapy and steroids. The 'cure' rates in the three corresponding groups were $38 \%$, $40 \%$, and $54 \%$. The only anomalous report is that from Great Ormond Street Children's Hospital (Lawson, Moncrieff, and Payne, 1960) in which the 'cure' rate without steroids was $53 \%$ and with steroids $40 \%$, and the death rate $32 \%$ without steroids and $45 \%$ with steroids. In Alder Hey Children's Hospital, comparison of experience for 1948 to 1955 (Todd, 1957) with the present series (1956 to 1964) shows a reduction in mortality from $34 \%$ to $11 \%$ and an increase of 'cure' from $44 \%$ to $78 \%$. There may well be an increase in the mortality rate and a decrease in the 'cure' rate as the follow-up period lengthens, but judging from our further observation of patients reported in 1957 (Todd) the cure rate should approach $70 \%$ after a minimum observation period of 3 years.

\section{Conclusions and Summary}

The clinical and biochemical features and the histological appearances of the biopsied kidney have been studied in 38 children, varying in age from 14 months to $13 \frac{1}{2}$ years, who were suffering from nephrosis.

Renal biopsy has contributed to our knowledge of this illness in three main ways. First, it has led to a more accurate diagnosis, not only by excluding such diseases as lupus erythematosus, Schönlein-Henoch purpura, amyloidosis etc., but also by demonstrating the nature of the renal changes, whether proliferative 
or membranous, and their extent. Secondly, it has influenced treatment, steroid therapy being likely to be successful in patients showing proliferative changes, whereas the value of steroids is doubtful when membranous changes are already present. Thirdly, prognosis can be more accurate; in general, patients showing proliferative changes have a better prognosis, largely because of the value of steroids in a lesion which is potentially reversible, whereas the prognosis is poor in patients already showing membranous changes.

Alterations in the levels of serum proteins can be related to some extent to the histological picture. In the proliferative group, the total serum protein levels are often very reduced, and $\gamma$-globulin is low, whereas in the membranous group, the total serum proteins are not reduced so much, and $\gamma$-globulin level is often normal or even raised.

The long-term prognosis for nephrosis is discussed in the light of the published reports; it has improved considerably over the past 4 decades and the threeyear 'cure' rate in children treated with antibiotics and steroids now approaches $70 \%$.

We wish to thank all our colleagues for their help in this study, especially the Consultant Paediatricians for allowing us access to their patients, Mr. Herbert Johnston who performed the renal biopsies, and Mr. J. T. Ireland for the biochemical investigations.

\section{REFERENCES}

Alwall, N. (1952). Aspiration biopsy of the kidney. Acta med. scand., $143,430$.

Arneil, G. C. (1961). 164 children with nephrosis. Lancet, 2, 1103.

Barness, L. A., Moll, G. H., and Janeway, C. A. (1950). Nephrotic syndrome. I. Natural history of the disease. Pediatrics, 5 , 486.

Blainey, J. D., Brewer, D. B., Hardwicke, J., and Soothill, J. F. (1960) The nephrotic syndrome. Quart. J. Med., 29, 235.

Bright, R. (1836). Cases and observations, illustrative of renal disease accompanied with the secretion of albuminous urine. Guy's Hosp. Rep., 1, 3838.

Dodge, W. F., Daeschner, C. W., Jr., Rosenberg, H. S., Brennan, J. C., Travis, L. B., and Hopps, H. C. (1962). Percutaneous renal biopsy in children. III. The nephrotic syndrome. Pediatrics, $30,459$.

Ellis, A. (1942). Natural history of Bright's disease. Lancet, 1, 1. Heptinstall, R. H. (1960). Chapter 4. In Recent Advances in Pathology, 7th ed., ed. C. V. Harrison, p. 89. Churchill, London.

Jungmann, P. (1924). Über chronische Streptokokkeninfektionen. Dtsch. med. Wschr., 50, 71.

Kark, R. M., Pirani, C. L., Pollak, V. E., Muehrcke, R. C., and Blainey, J. D. (1958). The nephrotic syndrome in adults: a common disorder with many causes. Ann. intern. Med., 49, 751.

Kramer, B., Goldman, H., and Cason, L. (1952). The treatment of the nonedematous nephrotic child with ACTH. J. Pediat., 41, 792.

Lawson, D., Moncrieff, A., and Payne, W. W. (1960). Forty years of nephrosis in childhood. Arch. Dis. Childh., 35, 115.

Müller, F. (1905). Morbus Brightii. Verh. dtsch. path. Ges., 9, 64

Ross, E. J., and Smith, J. F. (1963). The use of steroids in the treatment of the nephrotic syndrome in adults. Quart. J. Med., 32, 65.

Schwarz, H., Kohn, J. L., and Weiner, S. B. (1943). Lipid nephrosis. Amer. J. Dis. Child., 65, 355 .

Todd, R. McL. (1957). The natural history of nephrosis. Arch. Dis. Childh., 32, 99.

Volhard, F., and Fahr, T. (1914). Die Brightsche Nierenkrankheit. Springer, Berlin. 